Document downloaded from:

http://hdl.handle.net/10251/96983

This paper must be cited as:

Riera-Guasp, M.; Manuel Pineda-Sanchez; Pérez-Cruz, J.; Rubén Puche-Panadero; José Roger-Folch; J. Antonino-Daviu (2012). Diagnosis of induction motor faults via gabor analysis of the current in transient regime. IEEE Transactions on Instrumentation and Measurement. 61(6):1583-1596. doi:10.1109/TIM.2012.2186650

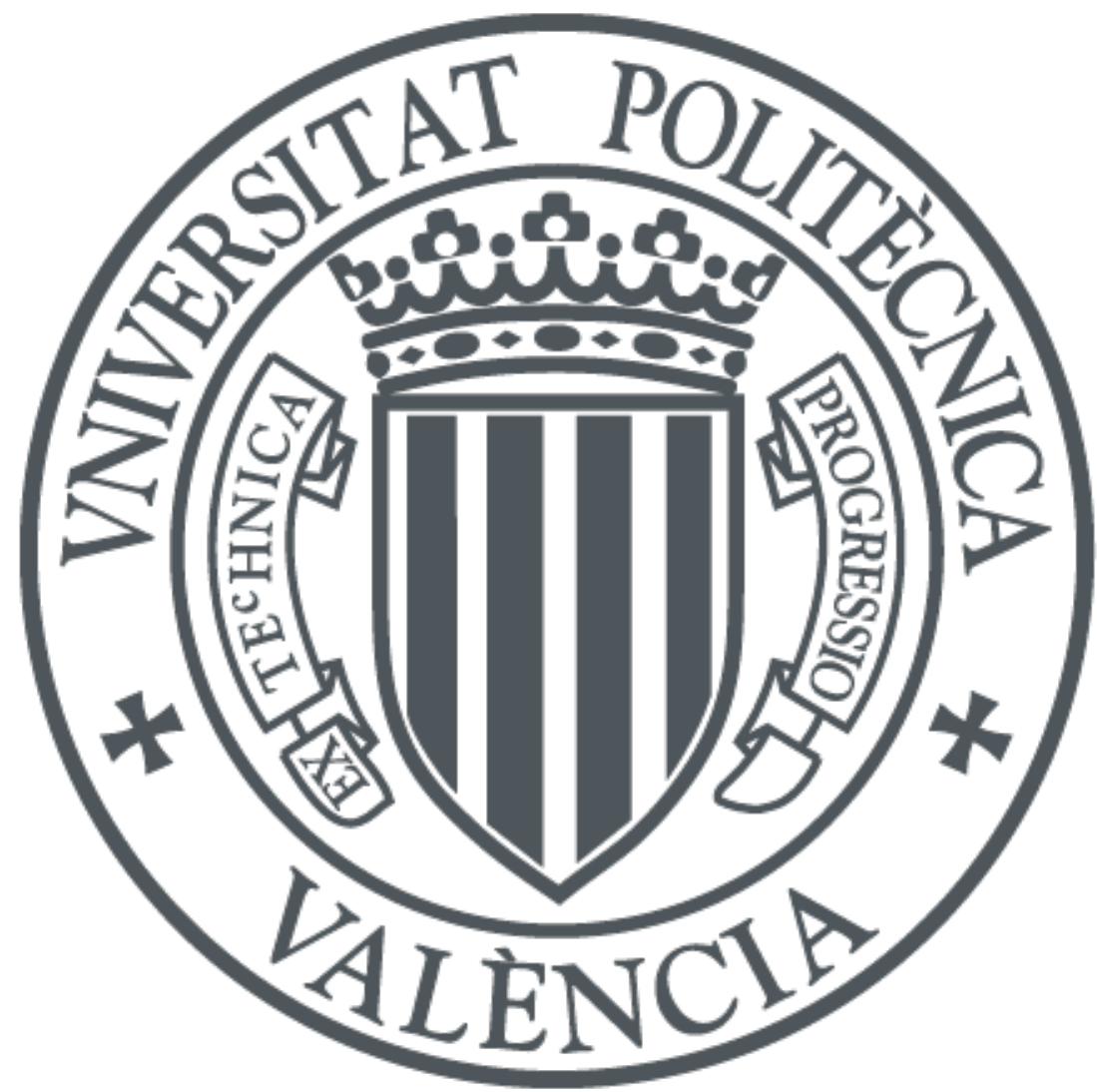

The final publication is available at

http:doi.org/10.1109/TIM.2012.2186650

Copyright IEEE-INST ELECTRICAL ELECTRONICS ENGINEERS INC

Additional Information 


\section{Diagnosis of Induction Motors Faults via Gabor Analysis of the Current in Transient Regime}

\begin{abstract}
Time-frequency analysis of the transient current in induction motors (IM) is the basis of the Transient Motor Current Signal Analysis (TMCSA) diagnosis method. IM faults can be accurately identified by detecting the characteristic figure that each type of fault produces in the time-frequency plane during a speed transient. Diverse transforms have been proposed to generate a 2D time-frequency representation of the current, such as the short time Fourier transform (STFT), the wavelet transform (WT), or the Wigner-Ville distribution (WVD). But a fine tuning of their parameters is needed in order to obtain a high resolution image of the fault in the time-frequency domain, and they also require a much higher processing effort than traditional diagnosis techniques, such as the Fourier Transform (FT). The new method proposed in this paper addresses both problems using the Gabor analysis of the current via the chirp z-transform (CZT), which can be easily adapted to generate high resolution time-frequency stamps of different types of faults. In this paper, it is used to diagnose broken bars of an IM using the current during a startup transient. This new approach is theoretically introduced and experimentally validated with a $1.1 \mathrm{~kW}$ commercial motor in faulty and healthy conditions.
\end{abstract}

Index Terms-Fault diagnosis, Induction motors, Timefrequency analysis, Fourier transforms, $Z$ transforms.

\section{INTRODUCTION}

$\mathrm{T}$ Hree-phase inductions motors are a key component of industrial installations. The detection of any IM failure at an early stage allows the replacement of damaged parts during scheduled maintenance operations, thus helping to reduce maintenance costs and to avoid costly, unexpected shutdowns. MCSA has become the de-facto standard method for IM diagnostics because it is non-invasive, and it can be performed on-line, without perturbing the operation conditions. MCSA is based on the detection of specific current harmonics with frequencies that are characteristic of each type of fault. For example, breakages in the rotor cage winding produce sideband components $f_{\mathrm{b}}$ in the line current spectrum around the fundamental [1], [2], at frequencies:

$$
\left.f_{b}(s)=(k / p(1-s) \pm s)\right) f_{1} \text { where } k / p=1,3,5 \ldots
$$

where $f_{1}$ is the supply frequency, $s$ is the rotor slip and $p$ the pole pairs number. The left sideband harmonic (LSH) is obtained by substituting $k / p=1$ in (1):

$$
f_{b}(s)=(1-2 \cdot s) \cdot f_{1} .
$$

As (1) and (2) indicates, the frequency associated to the fault depends on the motor slip, which may difficult the detection of the LSH using the FT spectrum: on the one hand, long sampling times are needed to obtain distinct spectral lines for the LSH, because its frequency is very near to the supply frequency (especially if the motor operates at very low slip, as in the case of light loads or high power motors even at rated load); on the other hand, during these long sampling times, load variations can produce slip oscillations that smear the spectrum [3]. Load variations can be avoided by analyzing the motor without any load [4], but in this case another problem arises: the LSH can be buried under the leakage of the mains spectral component. So, a minimum $30 \%$ of the rated load is recommended to perform MCSA [5]. Fig. 1 shows, for an experimental $1.1 \mathrm{~kW}$ motor whose characteristics are given in the appendix, the dependence of the LSH with the load, the problem of spectral leakage with light loads and the smearing of the spectrum at high load levels.

a)

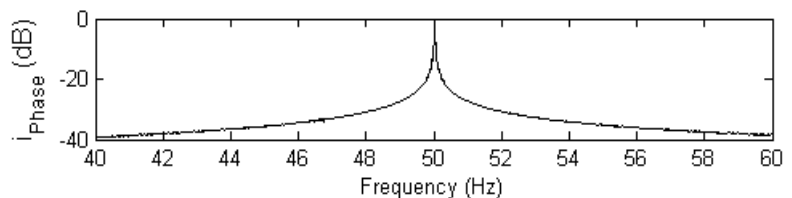

b)

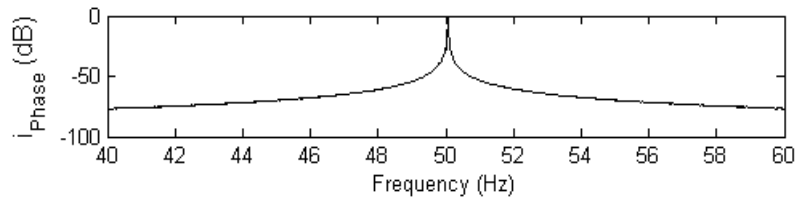

c)

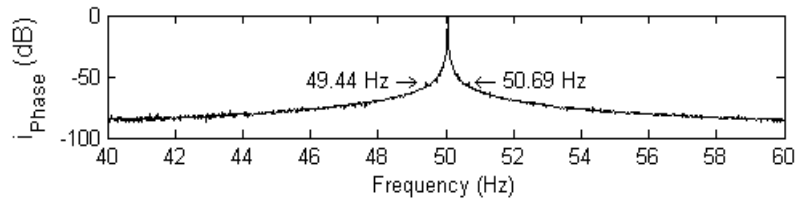

d)

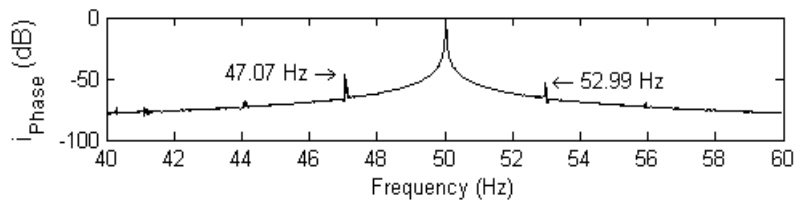

e)

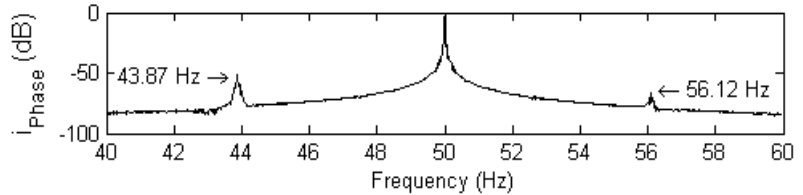

Fig. 1. Spectrum of the phase current of a motor with a broken bar in five experimental tests. Unloaded healthy machine (a), and machine with a broken bar under four different load conditions: unloaded (b), low load (c), medium load (d) and full load (e). The spectral leakage hides the LSH in (b) and (c). The LSH position depends on the load level. And smearing due to speed oscillations appears at rated load (e).

It has been also reported that, at certain slip values, some types of load (gearboxes [5]), motors with special characteristics ('spidered' rotor structures that have the same number of legs and poles [6]), or rotor asymmetries (rotor ellipticity, misalignment of the shaft with the cage or magnetic anisotropy [7]), can show up at the same frequency components of broken bars, triggering false alarms. So, instead of relying on a single slip value, [5] proposes a "two- 
test comparison", performing two MCSA tests at significantly different loads, with at least $40 \%$ difference between them.

This drawback, the dependence of the fault's frequency on the motor slip, is precisely the strength of time-frequency diagnostic methods, such as the one proposed in this paper. The evolution of the fault harmonic during a speed transient follows a characteristic trajectory in the time-frequency plane, which is unique for each type of fault. During the startup transient, the whole slip range $[1, \sim 0]$ is available to detect such a figure. Confusing frequencies may appear at certain slip values, but the global fault figure is not distorted, so timefrequency methods can be inherently more reliable than those which rely on a single frequency value. Fig. 2 depicts the characteristic V-shaped slip-frequency trajectory of the LSH during a startup transient (LSHst), as given by (2).

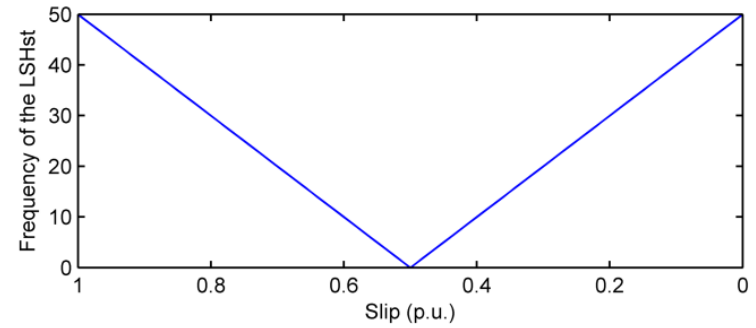

Fig. 2. Evolution of the frequency of the LSHst as a function of the rotor slip.

Specialized transforms are needed to convert the 1D (time domain) current signal into a 2D, time-frequency signal [8]. Linear transforms, such as the STFT [9]-[13] and the WT [9][26] or the Fractional FT [27], quadratic transforms, such as the WVD [9], [13], [28]-[30] or the Choi-Williams distribution (CWD) [31], or even data-driven transforms such as the Hilbert-Huang transform (HHT) [32]-[34] have been proposed to make such a conversion. The application of these advanced time-frequency transforms to motor diagnosis, nevertheless, have some drawbacks: quadratic transforms generate non-negligible cross-term artifacts in the timefrequency spectrum that can interfere with the actual fault frequencies, thereby diminishing the ability to precisely determine the severity of the fault (although some recent works suggest that new time-frequency distributions can provide strong cross term suppression [31]). The dependency on the data of HHT makes it difficult to adjust the frequencies of the transform to those characteristic of the fault. The performance of the time-frequency transform depends heavily on multiple parameters that must be fine-tuned to detect the LSHst. For example, in the case of the WT, as [35] points out, one criticism is the arbitrary choice of the mother wavelet function. [36] remarks that this choice is application dependent, and the method of choosing an appropriate basis is primarily been of trial and error. [37] indicates that the choice of the transform and the appropriate wavelet depends on the kind of information that we want to extract from the signal. In the case of the STFT, [13] remarks that the length of the sliding window determines time and frequency resolution, i.e., a good frequency resolution needs a long observation window and therefore leads to a bad localization in time and vice versa, so the window length has to be chosen based on a prior knowledge of the signal. Another major drawback is that timefrequency analysis requires much more computing resources than simple frequency-only analysis, which can limit its application in real-time fault diagnostic systems, as those implemented in FPGAs [19], [38], or DSPs [15], [39]-[41].

Both drawbacks are addressed in the new method presented in this paper: a Gabor analysis is applied to the startup current, using a Gaussian analyzing window and a detection lattice that are optimized, in the sense of minimum entropy, to detect the shape shown in Fig. 2. The analysis is carried out using the chirp z-transform, based on the FFT, which generates, in a fast and computationally efficient way, a high resolution image of the LSHst trajectory in the time-frequency domain. A machine fault, like a broken bar, is diagnosed by detecting the characteristic fault pattern in this representation.

Also, the diagnostic information generated by the timefrequency analysis of the current is presented as $2 \mathrm{D}$ or $3 \mathrm{D}$ images, providing a very rich and reliable information about the machine condition; certainly, the interpretation of these graphs requires an additional training effort of the maintenance personnel, more used to interpret traditional FT steady-state spectra; on the contrary, the main goal of other approaches as [27], based on the Fractional FT, is to translate the time-frequency information into spectrum-like graphs, easy to identify by non-specialized workforce, which is habituated to work with the FT.

Although the broken bar fault is used for the detailed presentation of the proposed method, it can be applied to diagnose other faults of the induction motor, such as eccentricity, bearing faults, inter-turns short circuits, by detecting and displaying the evolution in the time-frequency plane of their characteristics harmonics in transient regime.

The structure of this paper is the following one: in section II, the LSHst is characterized in the time-frequency domain. In section III, the theoretical basis of the Gabor analysis and the chirp z-transform are presented. In section IV the proposed method is optimized for the detection of the LSHst, and in section $\mathrm{V}$ it is experimentally validated with the analysis of two experimental $1.1 \mathrm{~kW}$ three-phase motors, one with a broken bar and the other one in healthy condition. In Section VI, the proposed method is applied to detect the eccentricity of a motor simulated with a finite elements program. Section VII presents the conclusions.

\section{EVOLUTION OF THE LSHST IN THE TIME-FREQUENCY PLANE}

The evolution of the LSHst has been analyzed by Riera et al. [17]. Fig. 3 shows its evolution in a simulated machine, considering only the fundamental space harmonic of its windings, sampled during $2 \mathrm{~s}$ at $5 \mathrm{kHz}$. The parameters of the machine are given in the appendix. The conditions selected for the simulation were: startup under no load with an inertia constant of $0.25 \mathrm{Kg} \cdot \mathrm{m}^{2}$.

Basically, the LSHst evolves as a sinusoidal wave whose frequency and amplitude vary continuously, following characteristic patterns. Two types of patterns can be identified out of Fig. 3, and they are represented in Fig. 4: a frequencytime pattern and an amplitude-time pattern. These patterns have been obtained from the analytic signal of the LSHst, $i_{L S H s t}(t)$, which is built using the Hilbert Transform (HT) [42]-[45]:

$$
i_{L S H s t}(t)=A(t) \cdot \exp (j \cdot \phi(t)) .
$$



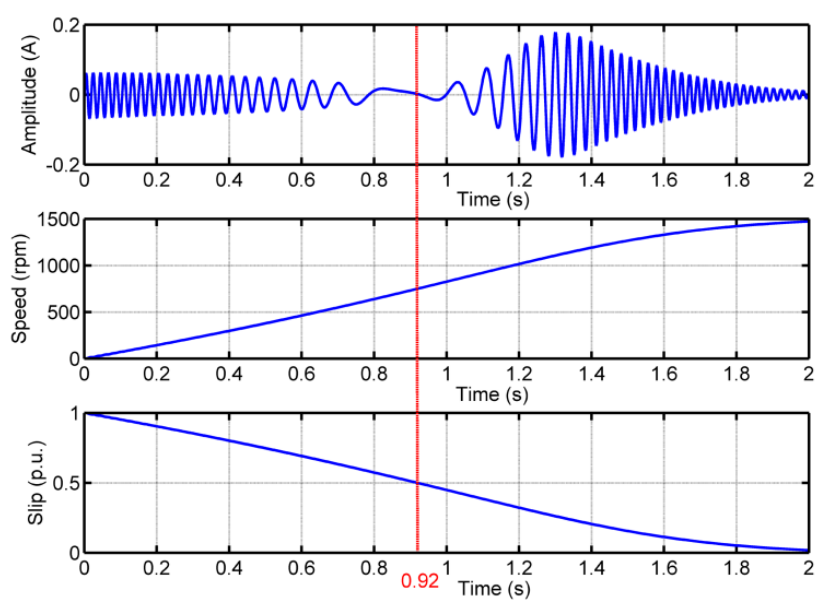

Fig. 3. Amplitude of the LSHst (top), motor speed (middle), and motor slip (bottom) during the startup transient of a simulated motor. The vertical line corresponds to the time when the slip $s=0.5$ is reached.
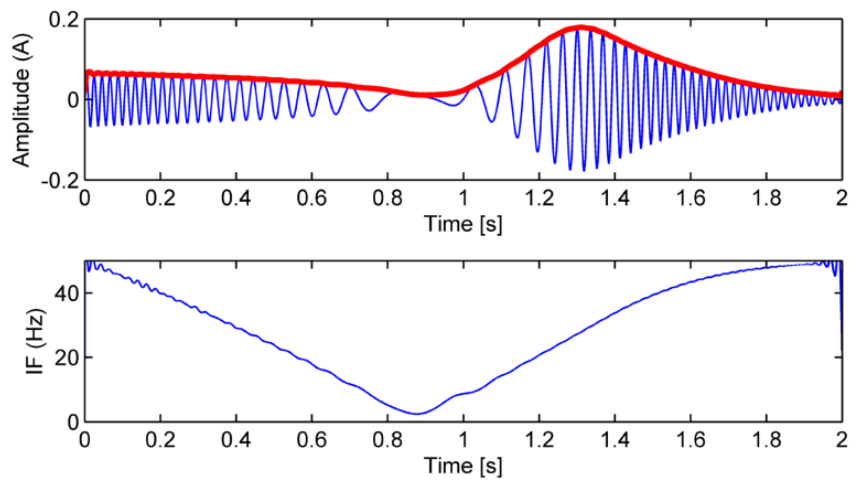

Fig. 4. Instantaneous amplitude (top, thick line) and instantaneous frequency (IF) of the LSHst (bottom), computed with the analytic signal.

The amplitude of the LSHst, $A(t)$, (Fig. 4, top, thick line) shows a characteristic evolution. Initially, from $t=0$, the amplitude decreases until the frequency becomes null. During the second half of the startup $(t>0.92 \mathrm{~s})$, the LSHst amplitude initially grows, reaches a maximum which exceeds the amplitudes reached during the first half of the startup, and then decreases towards its steady-state value.

The instantaneous frequency (IF) of the LSHst, $\phi^{\prime}(t)$, (Fig. 4, bottom) has a characteristic V-shape: it continuously decreases from the mains frequency $(50 / 60 \mathrm{~Hz})$ when the machine is connected $(t=0)$, becoming null when the rotor slip equals $0.5(t \approx 0.92 \mathrm{~s}$; see Fig. 3$)$. From this point, the frequency of the sideband component increases again, keeping a constant value when the stationary regime is reached. Both components are signals with linearly modulated frequency (LMF), also known as chirps.

So the goal of the proposed method is to capture the characteristic patterns presented in Fig. 4 directly from the startup motor current, by generating a unique 3D high resolution image (time, frequency and amplitude) that indicates the presence of the fault.

\section{GABOR ANALYSIS OF THE STARTUP CURRENT}

The method proposed in this paper is based on the Gabor analysis of the startup current, which is optimized for detecting the LSHst, and computed with the CZT. Gabor analysis has been extensively applied in different fields such as geophysics [46], pattern recognition [47], biomedical engineering [48], communications systems [49], image processing [50], [51], quality control [52], optics [53], power system analysis [54], [55], DNA classification [56], modal analysis [57], order tracking [58], etc. Gabor functions are the basis of the Morlet wavelet, which is widely used in machine condition monitoring [12], [16], [20]. The proposed method is applied in this work to extract the time-frequency information of the current during a speed transient, such as the startup. Its theoretical basis is briefly presented in this section.

Traditional MCSA relies on describing the motor current signal $i_{r}(t)$ in the frequency domain. This signal can be represented by a trigonometric series

$$
\begin{gathered}
i_{r}(t)=\sum_{n \in \mathbf{Z}} c_{n} \exp (j 2 \pi n t) \\
c_{n}=<i_{r}(t), \exp (j 2 \pi n t)>=\int_{-\infty}^{\infty} i_{r}(t) \exp ^{*}(j 2 \pi n t) d t
\end{gathered}
$$

where the superscript * stands for complex conjugation. So,

$$
i_{r}(t)=\sum_{n \in \mathbf{Z}}<i_{r}(t), \exp (j 2 \pi n t)>\exp (j 2 \pi n t) .
$$

Nevertheless, as the trigonometric basis functions $\{\exp (j 2 \pi n t), n \in \mathbf{Z}\}$ are not localized in time (because $|\exp (j 2 \pi n t)|=1$ for all $n$ and $t)$, (4) cannot reproduce the time-amplitude and time-frequency patterns shown in Fig. 4. The Fourier spectrum of the LSHst, shown in Fig. 5, is unable to capture these patterns. Due to the non-stationary character of the signal, its energy spreads over the full range of $0-50 \mathrm{~Hz}$, and there is no distinct peak in the spectrum that marks the presence of the fault harmonic.

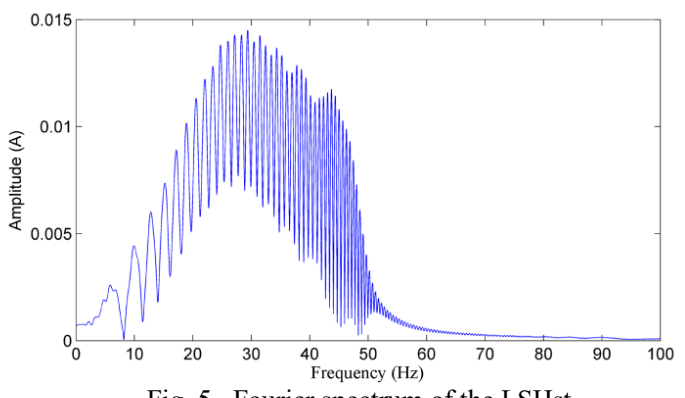

Fig. 5. Fourier spectrum of the LSHst.

On the contrary, Gabor analysis expands the signal $i_{r}(t)$ into a series of elementary functions, which are constructed from a single building block by translation and modulation (translation in the frequency domain), in the form

$$
i_{r}(t)=\sum_{m \in \mathbf{Z}} \sum_{n \in \mathbf{Z}} c_{m, n} g_{m, n}(t)
$$

where the elementary functions $g_{m, n}$ are given by

$$
g_{m, n}(t)=g(t-n \cdot T) \exp (j 2 \pi \cdot m \cdot \Omega \cdot t) \quad m, n \in \mathbf{Z}
$$

for a fixed function $g(t)$, known as the synthesis window, and time-frequency shift parameters $T, \Omega>0$. Besides, this function is subject to the energy normalization

$$
\int|g(t)|^{2} d t=1
$$


The functions $g_{m, n}$ in (7) are obtained by shifting the window $g$ along a lattice $\Lambda=T^{\prime} \times \Omega^{\prime}$ in the time-frequency plane. If $g$ and its FT are localized at the origin, then $g_{m, n}$ is localized at $(n \cdot T, m \cdot \Omega)$ in the time-frequency plane (Fig. 6).

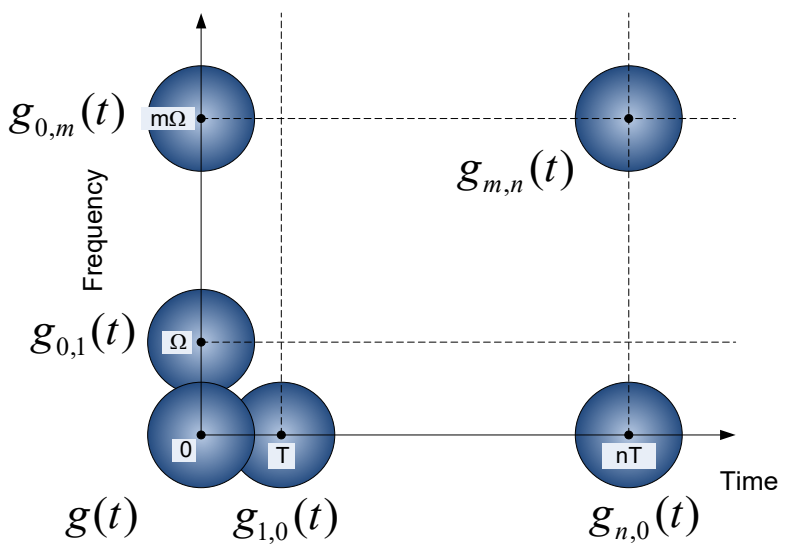

Fig. 6. Functions $g_{m, n}(t)$ obtained by shifting function $g(t)$ along a lattice $\Lambda=\mathrm{T}^{\prime}$ $\mathrm{x} \Omega^{\prime}$ in the time-frequency plane.

By Parseval's theorem

$$
\sum_{m \in \mathbf{Z}} \sum_{n \in \mathbf{Z}}\left|c_{m, n}\right|^{2}=\operatorname{Energy}\left(i_{r}(t)\right)
$$

so the coefficients $c_{m, n}$ can be interpreted as the measure of the energy of signal $i_{r}(t)$ in the area of the time-frequency plane covered by $g_{m, n}$.

The main issues related to the Gabor analysis of the startup current are the choice of the synthesis window $g$, the choice of lattice constants $T, \Omega$, and the way to compute coefficients $c_{m, n}$ in (7). As [59] points out, these choices are crucial as they affect the existence, uniqueness, convergence properties and numerical stability of the ensuing expansion. The choice of the parameters of the Gabor expansion is addressed in the following subsections, and these parameters are optimized for the detection of the LSHst signal.

\section{A. Choice of the type of the synthesis window}

As [60] points out, the choice of the synthesis window has a major effect on the concentration and resolution in the expansion (7). In general, it depends on the signal, and may differ for different components in the same signal. A common approach is to select the window based on minimizing the effective time-frequency area occupied by a given component [61], [62]. Other authors [46], [47], [53] and [63] even propose the use of separated kernels, with different parameters at different times. An open issue remains about how to measure the performance of the selected window.

In his original paper [64], Gabor proposed to use the Gauss function (11) and its translations and modulations with shift parameters $T \cdot \Omega=1$ (12) as elementary signals, or atoms:

$$
\begin{gathered}
g(t)=(\alpha / \pi)^{1 / 4} \exp \left(-\alpha t^{2} / 2\right) \\
g_{m, n}(t)=(\alpha / \pi)^{1 / 4} \exp \left(-\alpha(t-n T)^{2} / 2\right) \cdot \exp (j 2 \pi m \Omega t) .
\end{gathered}
$$

Other type of elementary functions that have been considered in the technical literature are the rectangle functions, the sync, the exponential [65], the chirp [48], [57], [60], [66], [67] and others [68]. In the proposed method, the choice has been the Gaussian function. The standard deviation of a Gaussian function (11), its duration $\sigma_{t}$, is given by

$$
\sigma_{t}^{2}=1 /(2 \alpha)
$$

so that in a time $2 \sigma_{t}$ most of the signal will have gone by. In fact, time series and Fourier series expansions are limiting cases of Gabor's series (7)

$\left\{\begin{array}{ccc}\sigma_{t} \rightarrow 0 & \Rightarrow \quad g_{m, n} \rightarrow \delta(t-n T) & \text { Time series expansion } \\ \sigma_{t} \rightarrow \infty & \Rightarrow \quad g_{m, n} \rightarrow \exp (j 2 \pi m \Omega t) & \text { Fourier series expansion }\end{array}\right.$

The FT of $g(t)$ is another Gaussian function $\hat{g}(f)$

$$
\hat{g}(f)=(1 / \alpha \pi)^{1 / 4} \exp \left(-(2 \pi f)^{2} / 2 \alpha\right) .
$$

The standard deviation of $\hat{g}(f)$, its bandwidth $\sigma_{f}$, is

$$
\sigma_{f}^{2}=\alpha / 8 \pi^{2}
$$

and multiplying (13) and (15), the following relation holds:

$$
\sigma_{t} \sigma_{f}=1 / 4 \pi
$$

The uncertainty principle states that one cannot construct any signal for which both $\sigma_{t}$ and $\sigma_{f}$, the duration of the signal and its bandwidth, are arbitrarily small

$$
\sigma_{t} \sigma_{f} \geq 1 / 4 \pi
$$

where equality is achieved only by the Gaussian function. So $g(t)$, as defined in (11), has the smallest area (i.e. the highest energy concentration) in the time-frequency plane that any given function can achieve, which justifies its choice for performing the decomposition (7). The Gaussian window (11) achieves minimum time-frequency uncertainty, and in this sense it is the most similar to an impulse [69]. Equations (13), (15) and (16) define the known as 'Heisenberg box' of the Gaussian window, [70], shown in Fig. 7.

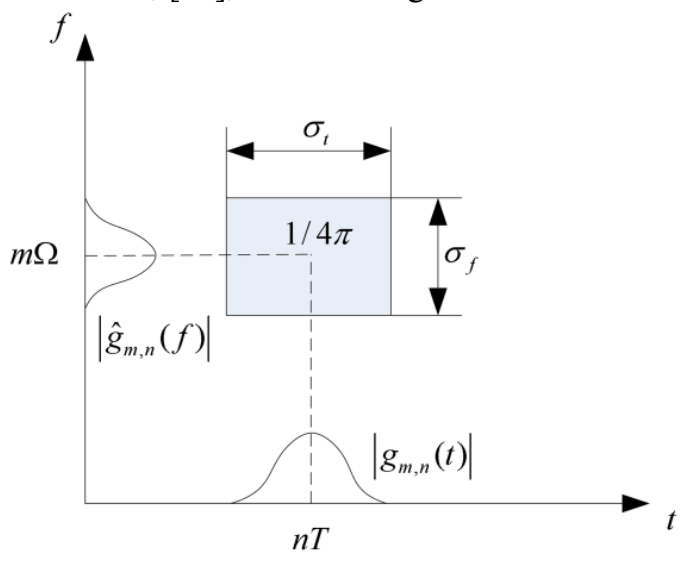

Fig. 7. Heisenberg box that encloses an atom $\boldsymbol{g}_{\boldsymbol{m}, \boldsymbol{n}}$. 


\section{B. Choice of the parameters of the synthesis window}

Once selected the type of the synthesis window $g(t),(11)$, it is necessary to select a value for its parameter $\alpha$, which defines both the duration (13) and the bandwidth (15) of $g(t)$. In [71] and [72] the optimal bandwidth of the window for signals with time-varying frequency is found to be equal to the square root of the time derivative of the instantaneous frequency of the signal. For [47] the optimum Gabor filter is the one with the highest sensitivity to the different components of the signal, and [60] selects the parameter that minimizes the timefrequency area occupied by a target component. To achieve this minimization in the proposed method, the time length of the Gaussian window is selected to have the maximum overlap with the LSHst signal. As the LSHst components are linear chirps with chirp rate given by (2), this condition is met when the slope of the chirp and the aspect ratio $\sigma_{f} / \sigma_{t}$ of the atom's Heisenberg box coincide (Fig. 8). This choice will be numerically assessed in section IV by minimizing the entropy of (7).

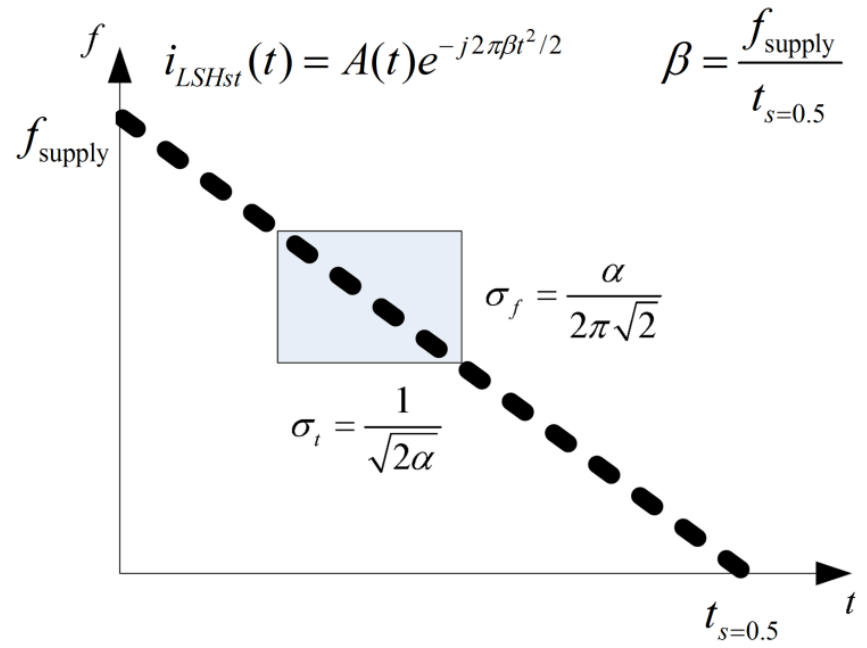

Fig. 8. Choice of parameter $\alpha$ of the Gaussian window so that the aspect ratio of its Heisenberg box coincides with the slope of the LSHst chirp.

The slope of the two chirps in the LSHst signal has a fixed, absolute value of $f_{\text {supply }} / 0.5$ (2) in the frequency-slope domain (Fig. 2). As the current signal is measured in the time domain, this slope is given by $f_{\text {supply }} / t_{s=0.5}$, where $t_{s=0.5}$ is the time needed to reach a slip $s=0.5$ during the startup transient. So, the maximum overlapping condition is combined with the uncertainty principle to give:

$$
\left.\begin{array}{c}
\sigma_{f} / \sigma_{t}=f_{\text {supply }} / t_{s=0.5} \\
\sigma_{f} \sigma_{t}=1 / 4 \pi
\end{array}\right\} \Rightarrow \sigma_{t}^{2}=t_{s=0.5} /\left(4 \pi f_{\text {supply }}\right) \text {. }
$$

Using (13), $\alpha=1 /\left(2 \sigma_{t}^{2}\right)$, gives finally

$g(t)=(\alpha / \pi)^{1 / 4} \exp \left(-\alpha t^{2} / 2\right)=\left(\frac{2 f_{\text {supply }}}{t_{s=0.5}}\right)^{1 / 4} \exp \left(-\frac{f_{\text {supply }}}{t_{s=0.5}} \pi t^{2}\right)$.

In the case of the LSHst of Fig. $4, t_{s=0.5}=0.92$ seconds and $f_{\text {supply }}=50 \mathrm{~Hz}$, so $g(t)=108.7^{1 / 4} \exp \left(-54.35 \pi t^{2}\right)$. This function is represented in separated (Fig. 9) and in combined time frequency planes (Fig. 10). In both cases the atom represented is the Gaussian window located at the center of the domain.
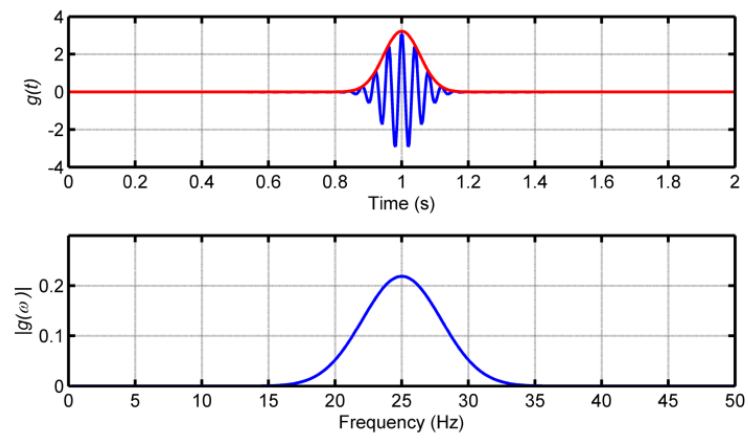

Fig. 9. Gaussian function optimized for representing the LSHst in the time (top) and in the frequency domains (bottom). The atom represented is the Gaussian window translated and modulated to the middle of the domain.

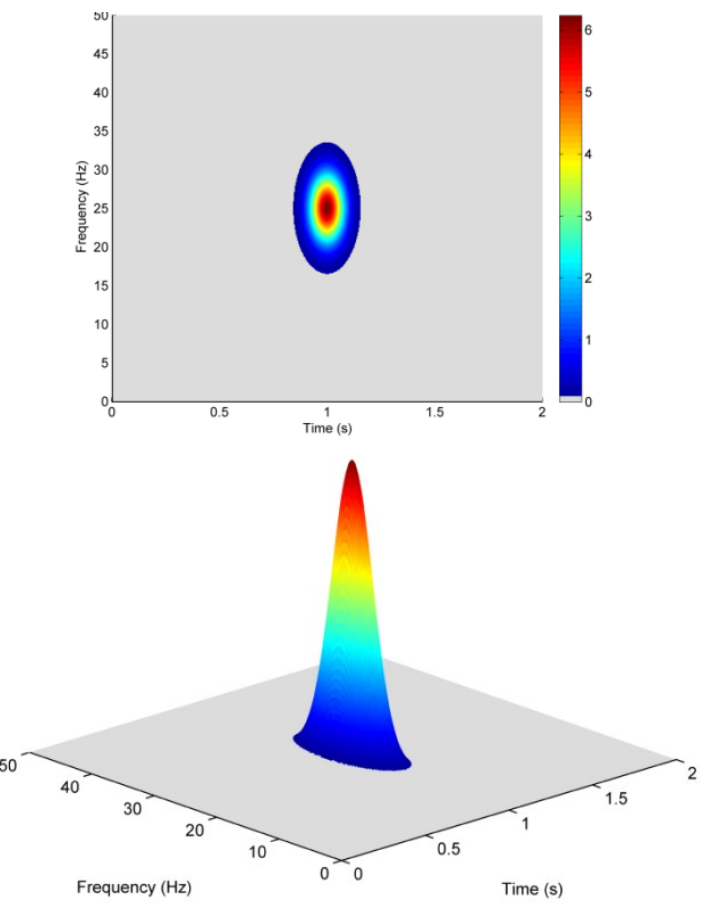

Fig. 10. Energy of the Gaussian function optimized for representing the LSHst as a 2D-view (top) and as a 3D view (bottom). The area covered by the function in the time-frequency plane is the smallest one under the uncertainty principle. The aspect ratio of this area has been optimized to have the maximum overlap with the LSHst signal.

\section{Choice of the lattice parameters $T, \Omega$}

Gabor's original choice $T \cdot \Omega=1$ results in the minimum lattice $\Lambda^{\prime}=T^{\prime} \times \Omega^{\prime}$ that covers completely the time-frequency plane, known as Gabor or Von Neumann Lattice [73], [74]. It corresponds to a critical sampling of the time-frequency plane. Nevertheless, a certain degree of oversampling $(T \cdot \Omega<1)$ is needed to avoid numerical instabilities (especially when processing noisy data), similar to the Fourier-Nyquist sampling limit. The choice of the degree of oversampling affects the computation of coefficients $c_{m, n}$ in (7). In fact, the basis functions $g_{m, n}$ are non-orthonormal: 


$$
<g_{n, l}, g_{m, k}>=\int g_{n l}(t) g_{m k}^{*}(t) d t \neq \delta_{n-m} \delta_{l-k}
$$

So coefficients $c_{m, n}$ cannot be computed by direct projection onto this basis, $c_{m, n} \neq<i_{r}, g_{m, n}>$. Instead, they must be computed using a translated and modulated window function $w(t)$, the analysis window, such that $c_{m, n}=<i_{r}, w_{m, n}>$ [75]-[80]. This window must satisfy the biorthonormality condition:

$$
<g_{m, k}, w_{n, l}>=\int g_{m, k}(t) w_{n, l}^{*}(t) d t=\delta_{n-m} \delta_{l-k}
$$

and so, the expansion (7) can be formulated as:

$$
i_{r}(t)=\sum_{m \in \mathbf{Z}} \sum_{n \in \mathbf{Z}}<i_{r}(t), w_{m, n}(t)>g_{m, n}(t) .
$$

The window $w(t)$ that satisfies (21) for the critically sampled Gabor's lattice has been derived analytically in [81], and it is represented in Fig. 11.

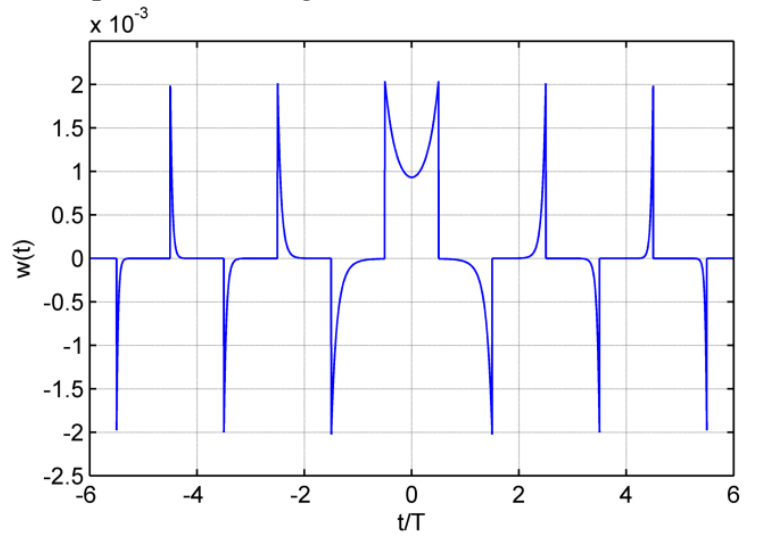

Fig. 11. Analysis window needed to compute the coefficients of Gabor's expansion on a critically sampled lattice.

As it can be seen in Fig. 11, the computation of the coefficients in a Gabor expansion on a critically sampled lattice is not local, and can lead to numerical instabilities [82]. One solution to this problem is the oversampling of the timefrequency plane, that is, the selection of $T$ and $\Omega$ so that $T \cdot \Omega<1$. [83] proposes the use of a maximum overlap in the sliding window. In fact, if $T \cdot \Omega \rightarrow 0$ the analyzing window $w(t)$ is the same as the synthesis window $g(t)$ [84]. Besides, with oversampling, the analysis gains in readability and in ease of interpretation what it loses in terms of saving space or computing time. So, with the choice of maximum oversampling

$$
c_{m, n}=<i_{r}, g_{m, n}>=\int i_{r}(t) g_{m, n}^{*}(t) d t .
$$

\section{Gabor analysis of the discrete current's signal via FFT}

From a practical point of view, the current signal $i_{r}(t)$ is sampled during a time $T_{S}$, at a frequency $F_{S}$, with $N=T_{S} \cdot F_{S}$ samples. The discretization process imposes minimum values for the time and frequency step:

$$
\begin{gathered}
\Delta t=T_{s} / N=T_{s} /\left(T_{s} F_{s}\right)=1 / F_{s} \\
\Delta f=F_{s} / N=F_{s} /\left(T_{s} F_{s}\right)=1 / T_{s}
\end{gathered}
$$

Using these values to obtain a lattice with maximum oversampling, ( $T=\Delta t, \Omega=\Delta f)$, (7) and (8) gives

$$
i_{r}(t)=\sum_{m \in \mathbf{Z}} \sum_{n \in \mathbf{Z}} c_{m, n} g(t-n \cdot \Delta t) \exp (j 2 \pi \Delta f \cdot m \cdot t) .
$$

Both the current signal and the elementary Gabor function are sampled at instants $t=k \Delta t$, giving two discrete sequences $i_{r}[k], g[k]$ with $N$ elements, and a matrix of $N \mathrm{x} N$ Gabor coefficients $c[m, n]$. (25) becomes then [49], [59]:

$$
i_{r}[k]=\sum_{m=0}^{N-1} \sum_{n=0}^{N-1} c[m, n] g[k-n] \exp \left(j \frac{2 \pi}{N} \cdot m \cdot k\right) \quad 0 \leq k<N .
$$

To avoid aliasing, all the original sequences have been previously zero-padded so as to double their size, and they are considered as periodic signals, with period $N$. All indices exceeding $N$ are understood modulo $N$ (without explicit notation).

The choice of maximum oversampling generates a lattice $\Lambda=\mathbf{Z}_{N} \times \mathbf{Z}_{N}$, with $\mathbf{Z}_{N}=\{0,1, \ldots, N-1\}$. In this case, the analyzing window $w[k]$ coincides exactly with the synthesis window $g[k]$, so Gabor coefficients are obtained (23) as

$$
c[m, n]=\sum_{k=0}^{N-1} i_{r}[k] g[k-n] \exp \left(-j \frac{2 \pi}{N} \cdot m \cdot k\right) \quad 0 \leq m, n<N .
$$

The evaluation of Gabor's coefficients using (27) can be time-consuming. A high value of $N$ is desirable for achieving a high resolution image. But this implies that (27) must be repeatedly evaluated $N \mathrm{x} N$ times to obtain the coefficients matrix $c[m, n]$. Nevertheless, this expression can be computed in a very efficient way. In fact, the Gabor analysis window $g_{m, n}$ acts as a band pass filter centered on frequency $2 \pi \mathrm{mN}$, with a bandwidth determined by $\alpha$. At each time, the time-shifted window is repeatedly shifted in the frequency axis, multiplied by the current's signal and summed up (27) to obtain a distribution of local energy measures of the signal [47]. But these repeated correlations in the frequency domain correspond to a simple element-wise product in the time domain. So, in (27) each column of the coefficients matrix is just the discrete Fourier transform (DFT) of the product of the current's signal with the time-shifted Gaussian window, which can be very effectively computed using the FFT.

$$
c[, n]=F F T\left(i_{r}[k] g[k-n]\right) .
$$

So Gabor analysis can be considered as a particular case of the STFT, performed with a Gaussian window, and the energy contents of the current signal in the time-frequency plane corresponds to its spectrogram [83], [85]. But this spectrogram corresponds to the signal expansion (7) only under the assumption of the maximum degree of oversampling, which has been achieved by using a displacement of the sliding window equal to the minimum time step of the discretization process (24).

\section{E. Gabor analysis of the discrete current's signal via CZT}

The analysis of the startup current (28) has a resolution problem: as stated in (24), time resolution can be improved by increasing the sampling frequency $F_{S}$, but the frequency resolution is limited by the total sampling time $T_{S}$. And, in the case of an IM startup transient, this time can be very short. In 
the case of the LSHst of Fig. $3\left(T_{S}=2 \mathrm{~s}, F_{S}=5 \mathrm{kHz}, N=10^{4}\right)$, $\Delta t=1 / F_{S}=10^{-4} \mathrm{sec}$ and $\Delta f=1 / T_{S}=0.5 \mathrm{~Hz}$. So, the number of points of the lattice used to represent the LSHst in the region of the time-frequency plane where the LSHst evolves ([0-2 s, $0-50 \mathrm{~Hz}])$ is $(2 / \Delta t) \times(50 / \Delta f)$, that is, $2 \cdot 10^{4} \times 100$ points. This gives a much distorted lattice, with a very few frequency intervals (100), compared with the number of time intervals $\left(2 \cdot 10^{4}\right)$. To solve this problem, in the proposed method, the FFT is replaced with the CZT [4], [11], [86]-[92]. The FFT evaluates the frequency spectrum of a signal in the whole range $0-F s$, as a $z$-transform of the signal following a full circular path with unitary radius. The CZT algorithm is more flexible, as it can follow any desired path in the z-plane. In particular, it can be adjusted to evaluate the DFT in a reduced range of frequencies, using the full number of signal samples, but covering a small fraction of the unity circumference. In this way, a much better spectral resolution is obtainable, compared with the FFT. This fact has been exploited in [16] to perform rotor fault diagnosis and in [93] to improve the accuracy in motor speed measurement. In the case of the LSHst of Fig. 4, the frequency band of interest is [0-50 Hz], which gives a spectral resolution:

$$
\Delta f^{\prime}=50 / N=50 /\left(2 \cdot 10^{4}\right)=25 \cdot 10^{-4} \mathrm{~Hz} .
$$

So the lattice used to represent the LSHst has $(2 / \Delta t) \times\left(50 / \Delta f^{\prime}\right)$, that is, $2 \cdot 10^{4} \times 2 \cdot 10^{4}$ points. Gabor coefficients are computed in this high resolution lattice as

$$
c[;, n]=C Z T\left(i_{r}[k] g[k-n]\right) .
$$

\section{ANALYSIS OF THE LSHST USING THE PROPOSED METHOD}

The proposed method for generating a high resolution image of the LSHst trajectory in the time-frequency plane can be summarized as follows:

1. Determine the time needed to reach a slip $s=0.5$ during the startup transient, $T_{s=0.5}$. This gives the slope of the first chirp component of the LSHst.

2. Construct a Gaussian window whose Heisenberg box has an aspect ratio $\sigma_{f} \sigma_{t}$ that matches the chirp slope, using (19).

3. Compute the matrix of Gabor coefficients $c[m, n]$ using (30). Each column $n$ contains the CZT of the product between the startup current and the analyzing window, which has been previously shifted $n$ samples from the origin. The squared Gabor coefficients display the local energy content of the startup current at each point of the time-frequency lattice.

The application of the proposed method to the LSHst of Fig. 3 generates a high resolution 3D image (time-frequencyamplitude) which shows the trajectory of the fault harmonic in the time frequency plane, as depicted in Fig. 12.

In the case of the LSHst, the parameter $\alpha$ of the optimal Gaussian window, obtained with (18), has a value $\alpha_{\text {opt }}=341.5$. The validity of this particular choice, and the sensitivity of the method to variations of this parameter, can be measured via the entropy of the normalized Gabor coefficient matrix [8], [94]:

$$
e=-\sum_{m=0}^{N-1} \sum_{n=0}^{N-1} \frac{c[m, n]^{2}}{\lambda_{m, n}} \log \left(\frac{c[m, n]^{2}}{\lambda_{m, n}}\right)
$$

with

$$
\lambda_{m, n}=\sum_{m=0}^{N-1} \sum_{n=0}^{N-1} c[m, n]^{2}
$$

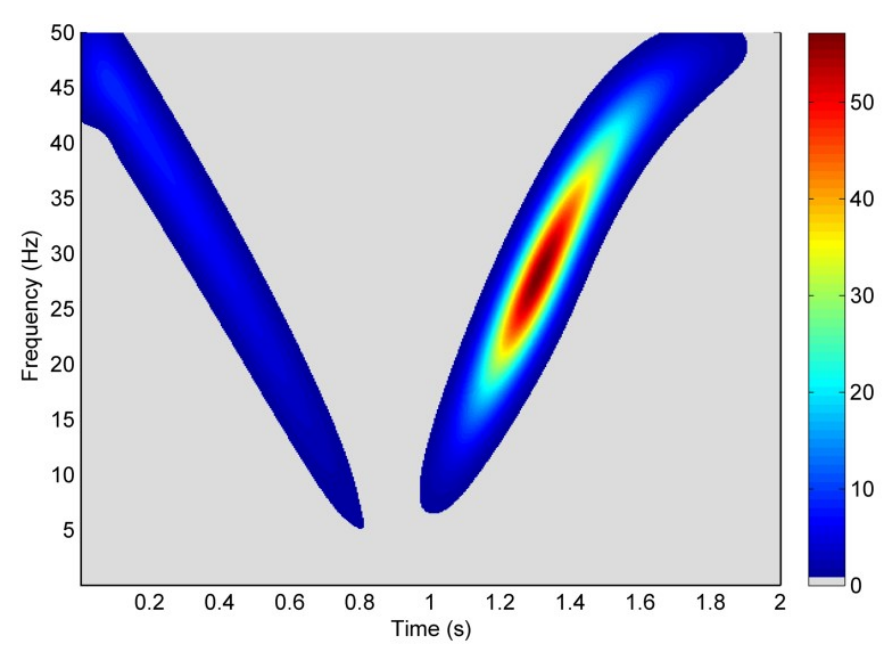

Fig. 12. Time-frequency-amplitude pattern generated by the LSHst, obtained with the proposed method.

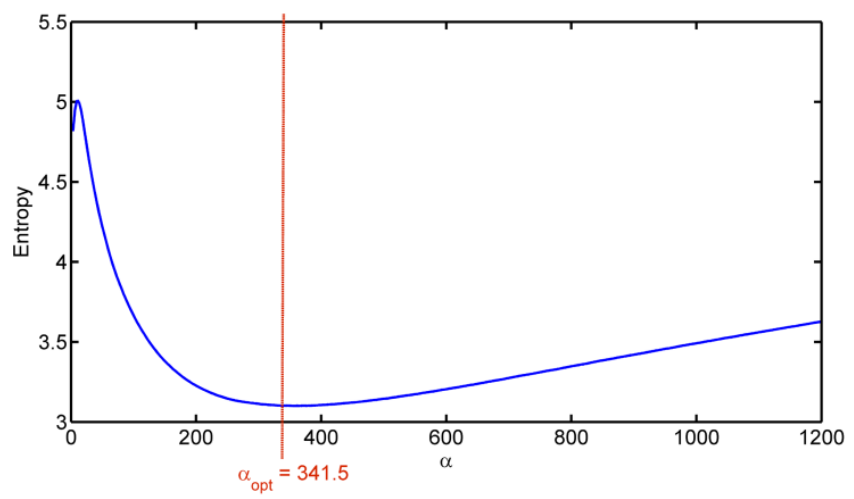

Fig. 13. Entropy of the Gabor expansion of the LSHst as a function of the parameter $\alpha$ of the Gaussian analyzing window. The vertical line marks the value obtained by applying the criteria of maximum overlapping between the window and the LSHst, as in the proposed method.

Small entropy corresponds to good energy concentration. Fig. 13 shows the entropy (31) of the LSHst series expansion (7), for values of parameter $\alpha$ in (19) varying from 1 to 1200.

Two conclusions can be drawn from Fig. 13: first, the rule used for selecting the optimal value of $\alpha$ (19) corresponds indeed to the choice of minimum entropy (maximum energy concentration) of the LSHst representation in the timefrequency plane $\left(\alpha_{\mathrm{opt}}=341.5\right.$, entropy $\left.=3.102\right)$. And, second, the entropy curve around this optimal value is a smooth one. This indicates that the computation process of $\alpha$ (19) can tolerate small errors in determining the $t_{s=0.5}$ value. For example, if the motor speed cannot be measured, $t_{s=0.5}$ can be roughly estimated as half of the total startup transient duration, $t_{s=0.5} \approx 1$ s. Using this approximate value instead the real one, $\alpha^{\prime}{ }_{\mathrm{opt}}=314.16$, gives an entropy of 3.108. This represents a very small deviation from the minimal entropy, so the Gabor 
representation of the LSHst obtained with this approximated value of $t_{s=0.5}$, shown in Fig. 14, is very similar to the one obtained with the exact value of $\alpha_{\text {opt }}$ (Fig. 12)

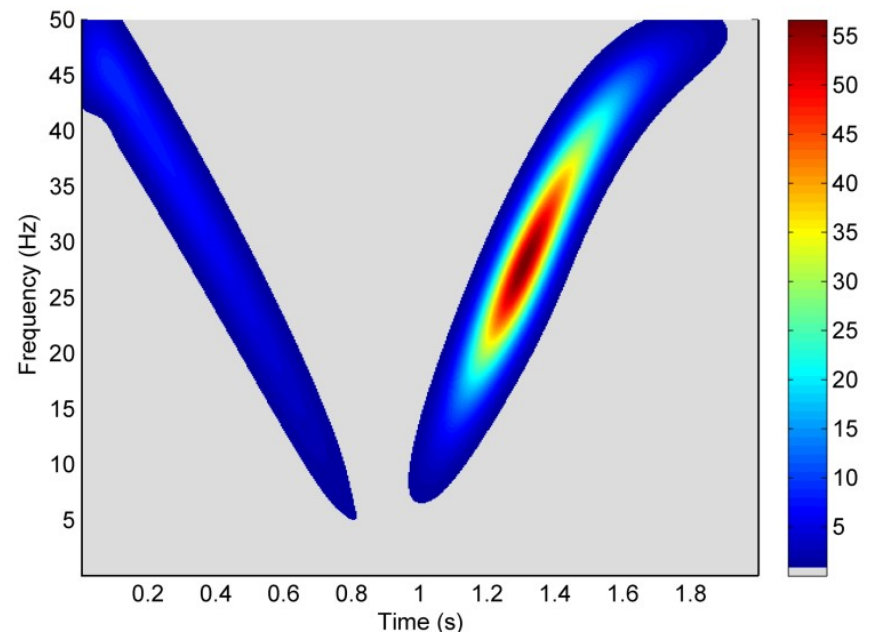

Fig. 14. Time-frequency-amplitude pattern generated by the LSHst, obtained with the proposed method without measurement of the motor speed.

\section{EXPERIMENTAL SETUP}

The proposed method has been applied to the analysis of a $1.1 \mathrm{~kW}, 50 \mathrm{~Hz}$ induction motor, whose data are given in Appendix A. The test equipment, displayed in Fig. 15, left, consists of a current transformer, a 200 pulse/revolution incremental encoder, a Yokogawa DL750 Oscilloscope and a Personal Computer connected to it via an intranet network.

Tests have been carried out under two different conditions: healthy state and faulty condition, in which a single bar has been broken by drilling a hole in the selected bar (Fig. 15, right). In both cases the operating conditions are identical: the supply voltage is $160 \mathrm{~V}$, and the machine is started at no load, driving a pure inertia load with an inertia constant of $\mathrm{J}=0.0024$ $\mathrm{kg} . \mathrm{m}^{2}$. The startup current and the speed have been recorded during 2 seconds using a sampling frequency of $10 \mathrm{kHz}$. Fig. 16 shows the current and the speed of the motor with a broken bar during a startup transient.

The proposed method has been applied to the current shown in Fig. 16. In this case $t_{s=0.5}=0.63 \mathrm{~s}$, so (19) gives

$$
g(t)=(158.73)^{1 / 4} \exp \left(-79.36 \pi t^{2}\right)
$$

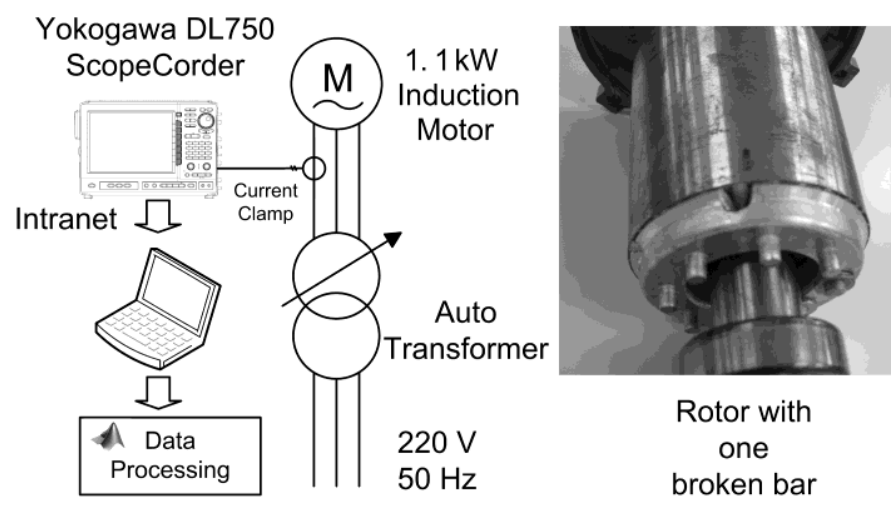

Fig. 15. Experimental setup used for validation of the methodology.
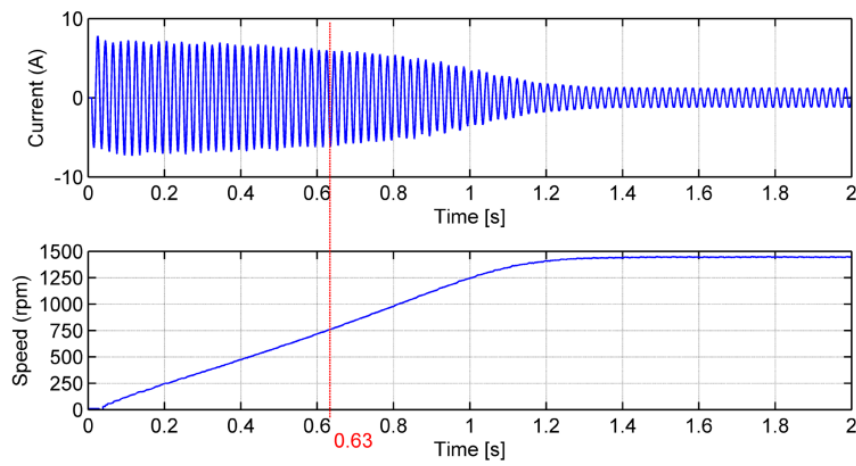

Fig. 16. Current (top) and speed (bottom) of the experimental motor with a broken bar during the startup transient. The vertical line corresponds to the time when the slip $s=0.5$ is reached $\left(t_{s=0.5}\right)$.

Fig. 17 shows the squared Gabor coefficients of this signal, obtained via CZT.
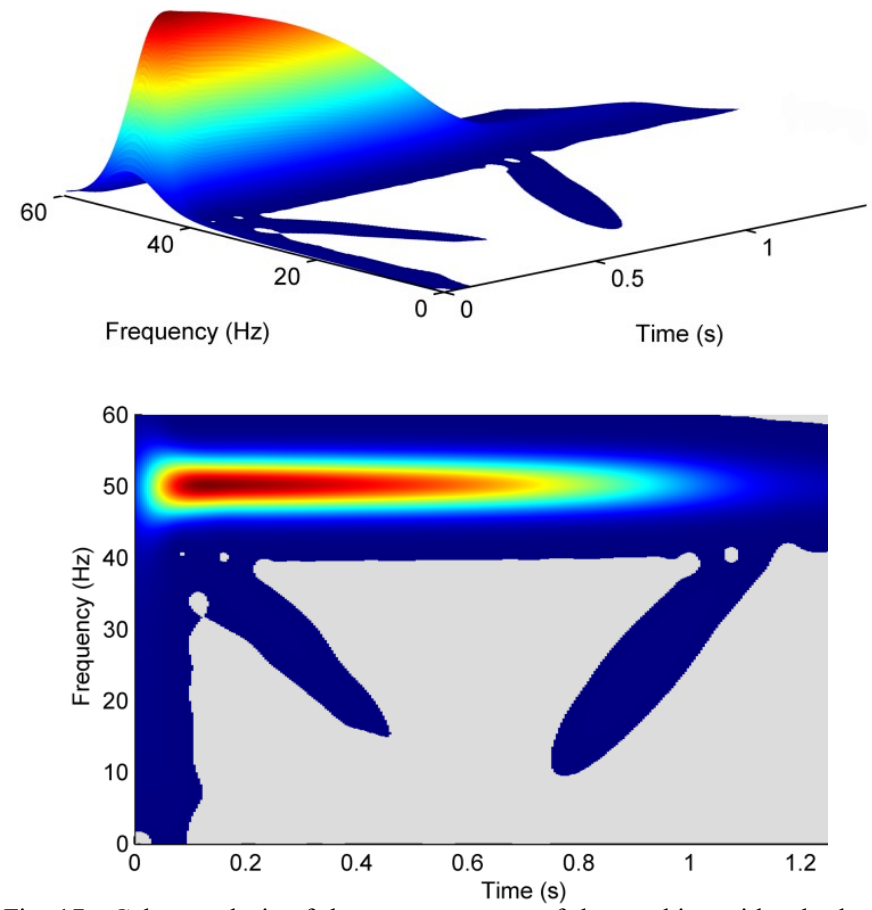

Fig. 17. Gabor analysis of the startup current of the machine with a broken bar. Top: 3D view. Bottom: 2D view.

The Gabor analysis of the current's signal, using the window (33), is shown in Fig. 17. Two problems arise in this representation: the main component of the current has a much higher value than that of the LSHst, which is not well resolved, and the end effects of the CZT (Gibb's phenomenon) appear at the beginning of the transient. To solve these problems, the upper limit of the frequency range has been reduced to $40 \mathrm{~Hz}$, and the initial region, where the end effects occur, has not been represented. The results are shown in Fig. 18 , where the trajectory of the LSHst is clearly identified in the time-frequency plane. 


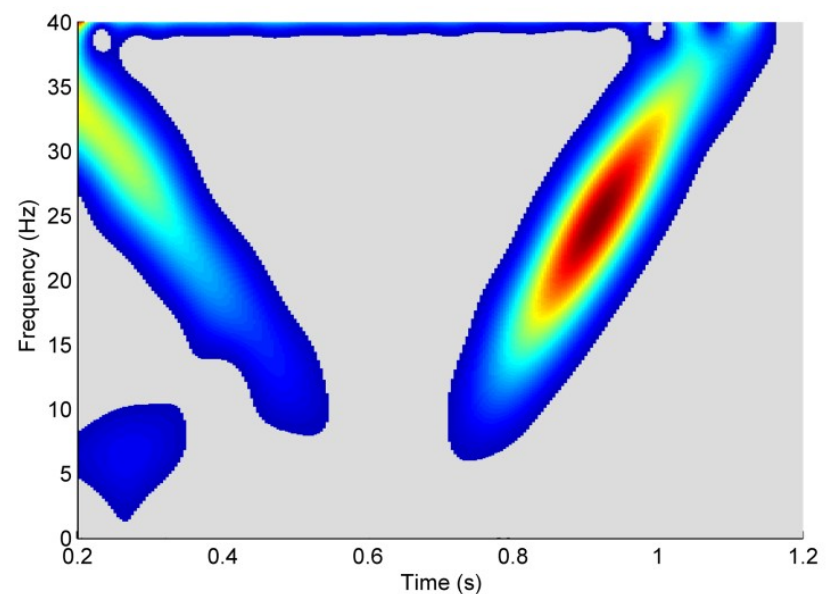

Fig. 18. Gabor analysis of the startup current of the machine with a broken bar, avoiding the effects of the mains leakage and the end effects of the transform.

The same analysis has been made with a healthy motor, with the same characteristics than the healthy one, under the same startup conditions. Fig. 19 shows the startup current of this motor, and Fig. 20 the Gabor analysis of this current, using the proposed method. There is no trace of the LSHst in this figure, so the diagnostic is of a healthy motor condition.
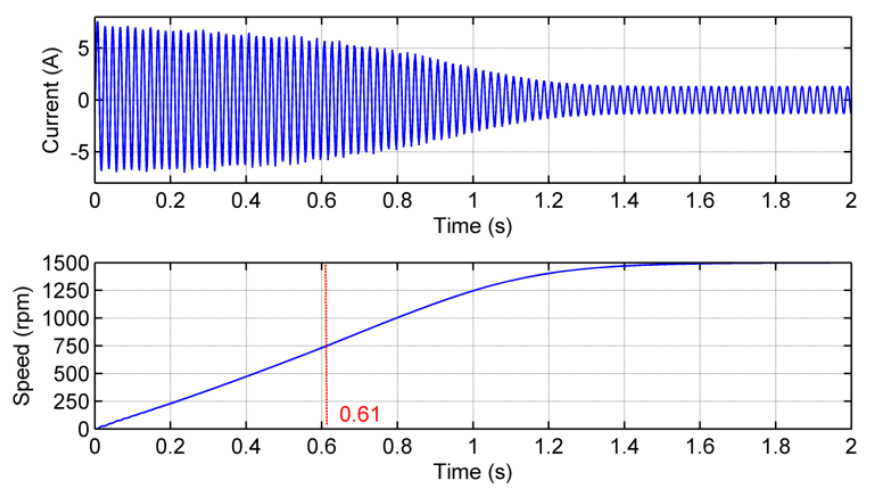

Fig. 19. Current (top) and speed (bottom) of the experimental healthy motor during the startup transient. The vertical line corresponds to the time when slip $s=0.5$ is reached.

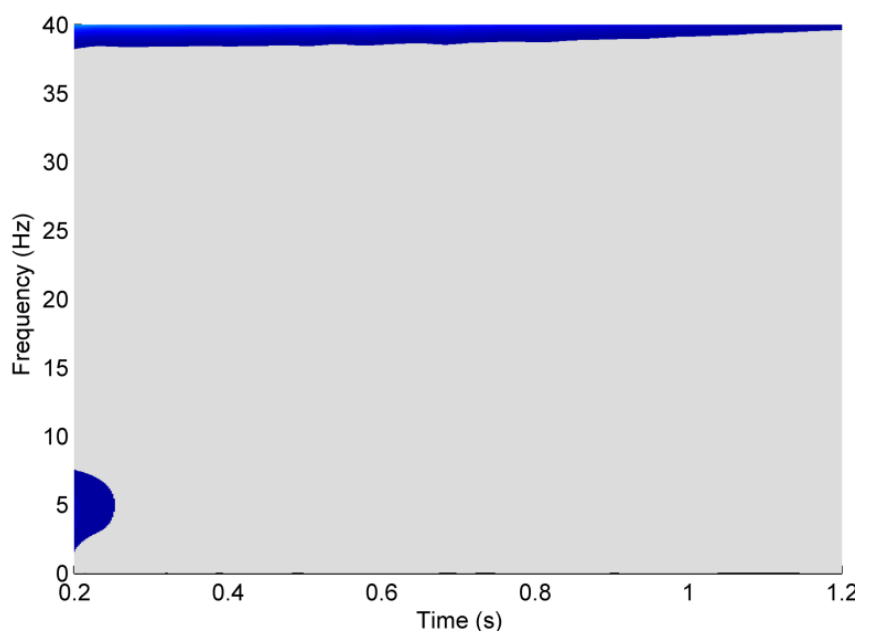

Fig. 20. Gabor analysis of the startup current of the healthy machine, excluding the effects of the mains and the end effects of the transform.

\section{DETECTION OF A MIXED ECCENTRICITY FAULT WITH THE PROPOSED METHOD}

The proposed method can be applied to the detection of any fault that generates LMF harmonics in transient regime: eccentricity, bearings faults, inter-turns short circuits, etc. It suffices to adjust the aspect ratio of the synthesis window, the value of $\alpha$ in (11), to the theoretical slope of the fault harmonic. In this section, the proposed method is applied to the diagnosis of a mixed eccentricity (ME) fault. An ME fault can be detected by the presence of its characteristic harmonics, whose frequencies are given by

$$
f_{M E}(s)=f_{\text {supply }} \pm(1-s) f_{\text {supply }} / p
$$

An eccentric four pole induction machine, whose characteristics are given in Appendix A, has been prepared for the experimental validation of the proposed method. The static and dynamic eccentricities have been obtained through the machining of the external and internal bearing housings, respectively. Fig. 21 shows the assembled unit and its components (top), and the unit mounted in the shaft (bottom). The degree of eccentricity obtained with this experimental unit is $30 \%$ of static eccentricity and $50 \%$ of dynamic eccentricity.

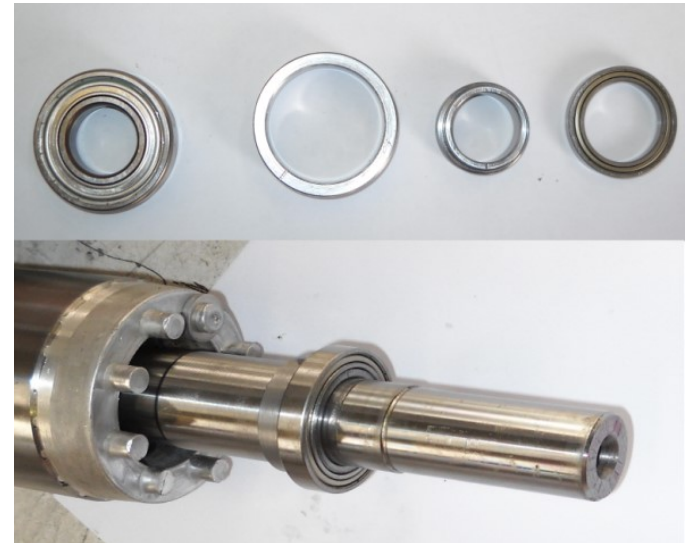

Fig. 21. Eccentric motor unit. Top, from left to right: assembled unit, asymmetric external and internal housings, and healthy bearing. Bottom: mounted unit on the shaft.

The motor has been fed at rated voltage, and it has been mechanically coupled to a high inertia, non-energized synchronous generator, to obtain a longer startup transient. The current and the peed during this transient are shown in Fig. 22.
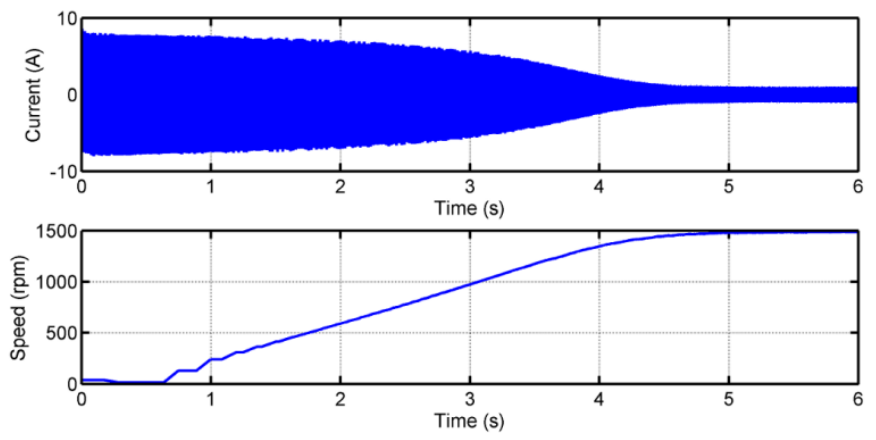

Fig. 22. Current (top) and speed (bottom) of the experimental eccentric motor during the startup transient. 
In the case of $p=2,(34)$ becomes

$$
f_{M E}(s)=f_{\text {supply }} \pm(1-s)\left(f_{\text {supply }} / 2\right)
$$

As (35) indicates, during a startup transient, the lower characteristic harmonic of an $\mathrm{ME}$ fault, $i_{M E s t}(t)$, follows a straight path in the time-frequency plane, travelling from $f_{\text {supply }}$ at $s=1$ to $f_{\text {supply }} / 2$ at $s \approx 0$ (steady regime), so

$$
i_{M E s t}(t)=A(t) e^{-j 2 \pi \beta t^{2} / 2} \quad \text { with } \quad \beta=\frac{f_{\text {supply }} / 2}{t_{s \approx 0}}
$$

Following the same process described in detail in Section III, the synthesis window (11) whose aspect ratio matches the harmonic's slope $\beta$ in (36) is given by

$$
g(t)=(\alpha / \pi)^{1 / 4} \exp \left(-\alpha t^{2} / 2\right)=(2 \beta)^{1 / 4} \exp \left(-\beta \pi t^{2}\right)
$$

Using the values of the machine startup current and speed represented in Fig. $22\left(f_{\text {supply }}=50 \mathrm{~Hz}, \mathrm{t}_{s} \approx 0 \approx 5 \mathrm{~s}\right)$, the synthesis window (37) becomes

$$
g(t)=(10)^{1 / 4} \exp \left(-5 \pi t^{2}\right)
$$

Due to the symmetric nature of both ME harmonics, the Heisenberg box given by (38) is valid for both of them. The Gabor analysis of the current's signal, using the window (38), is shown in Fig. 23, where the upper and lower ME fault characteristic harmonics are clearly visible around the fundamental component.

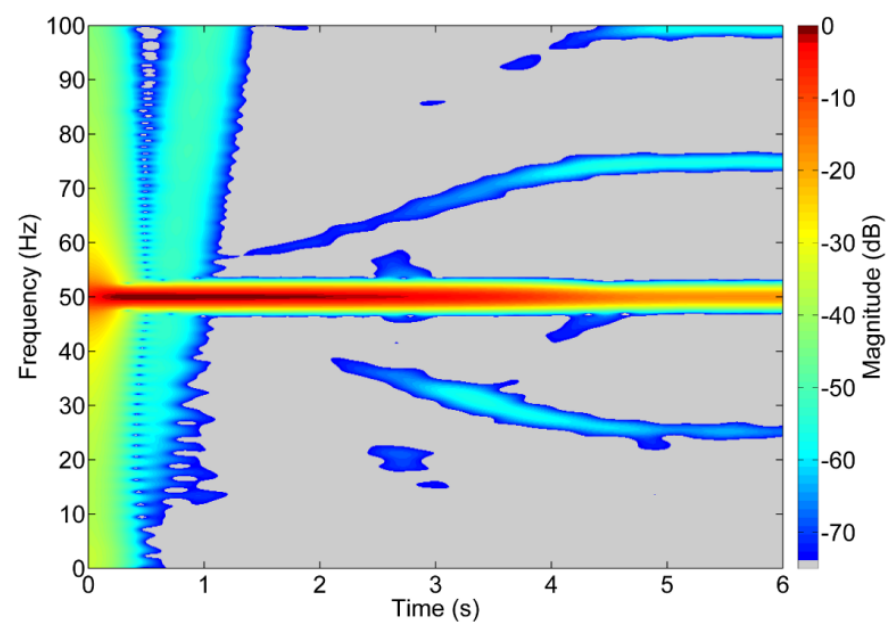

Fig. 23. Gabor analysis of the startup current of the eccentric machine, showing the characteristic fault harmonics of the fault.

As in the preceding section, if the upper limit of the frequency range is reduced (to avoid the strong influence of the mains current), and the initial region (where the end effects occur) is not represented, the lower fault harmonic appears very clearly (see Fig. 24), which facilitates the diagnosis process.

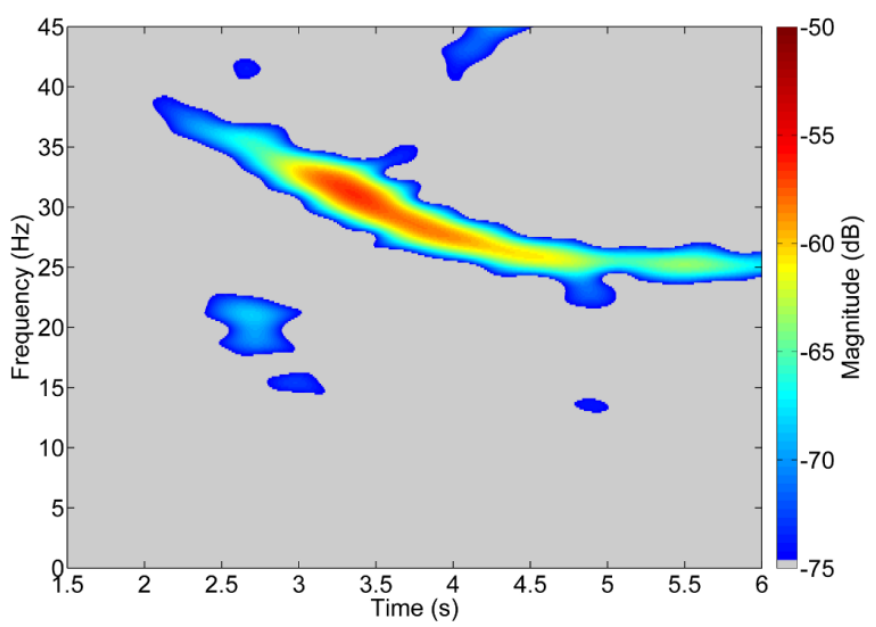

Fig. 24. Gabor analysis of the startup current of the eccentric machine, avoiding the effects of the mains leakage and the end effects of the transform.

\section{CONCLUSIONS}

Transient MCSA is a recent technology that can diagnose motor faults by analyzing the current during a speed transient. With the addition of a new dimension in TMCSA, the time, new methods capable of representing the time-frequencyamplitude of the fault harmonics are needed to replace traditional FT based methods, which are not designed to cope with non-stationary signals. In this paper, a new method has been proposed for detecting the characteristic harmonics that induction motor faults generate during a transient regime, such as those generated by broken bars during a startup transient (LSHst) or by mixed eccentricity (MEst). The startup current is analyzed using a Gaussian window. The combined use of a matched window, a maximally oversampled lattice and the chirp z-transform, allow for the generation of a very high resolution image of the trajectory of these harmonics, with the highest concentration in the time-frequency domain (minimum entropy). This new method has been theoretically presented, numerically optimized, and experimentally validated with three industrial $1.1 \mathrm{~kW}$, three-phase induction motors, one in healthy state, one with a broken bar and the other one with a mixed eccentricity fault. The application of the proposed method to other types of fault is currently under research.

\section{APPENDIX A}

MACHINE USED IN THE EXPERIMENTAL TESTS

Machine parameters: Three-phase induction motor. Rated characteristics: $P=1.1 \mathrm{~kW}, f=50 \mathrm{~Hz}, U=230 / 400 \mathrm{~V}, I=2.7 / 4.6$ $A, n=1410 \mathrm{rpm}, \cos \varphi=0.8$.

\section{REFERENCES}

[1] G. B. Kliman, R. A. Koegl, J. Stein, R. D. Endicott, and M. W. Madden, "Noninvasive detection of broken rotor bars in operating induction motors," IEEE Trans. Energy Convers., vol. 3, pp. 873-879, 1988.

[2] A. Bellini, F. Filippetti, G. Franceschini, C. Tassoni, and G. B. Kliman, "Quantitative evaluation of induction motor broken bars by means of electrical signature analysis," IEEE Trans. Ind. Appl., vol. 37, pp. 1248$1255,2001$.

[3] W. T. Thomson and M. Fenger, "Current signature analysis to detect induction motor faults," IEEE Industry Applications Magazine, vol. 7, pp. 26-34, 2001.

[4] R. Puche-Panadero, M. Pineda-Sanchez, M. Riera-Guasp, J. RogerFolch, E. Hurtado-Perez, and J. Perez-Cruz, "Improved Resolution of the 
MCSA Method Via Hilbert Transform, Enabling the Diagnosis of Rotor Asymmetries at Very Low Slip," IEEE Trans. Energy Convers., vol. 24, pp. 52-59, 2009.

[5] M. C. Ian and R. Wendell, "Using Current Signature Analysis Technology to Reliably Detect Cage Winding Defects in Squirrel-Cage Induction Motors," IEEE Trans. Ind. Appl., vol. 43, pp. 422-428, 2007.

[6] A. Bellini, F. Filippetti, G. Franceschini, C. Tassoni, R. Passaglia, M. Saottini, G. Tontini, M. Giovannini, and A. Rossi, "On-field experience with online diagnosis of large induction motors cage failures using MCSA," IEEE Trans. Ind. Appl., vol. 38, pp. 1045-1053, 2002.

[7] B. Yazici and G. B. Kliman, "An adaptive statistical time-frequency method for detection of broken bars and bearing faults in motors using stator current," IEEE Trans. Ind. Appl., vol. 35, pp. 442-452, 1999.

[8] E. Sejdic, I. Djurovic, and J. Jiang, "Time-frequency feature representation using energy concentration: An overview of recent advances," Digital Signal Processing, vol. 19, pp. 153-183, 2009.

[9] E. G. Strangas, S. Aviyente, and S. S. H. Zaidi, "Time-Frequency Analysis for Efficient Fault Diagnosis and Failure Prognosis for Interior Permanent-Magnet AC Motors," IEEE Trans. Ind. Electron., vol. 55, pp. 4191-4199, 2008.

[10] J. Cusido, L. Romeral, J. A. Ortega, J. A. Rosero, and A. Garcia Espinosa, "Fault Detection in Induction Machines Using Power Spectral Density in Wavelet Decomposition," IEEE Trans. Ind. Electron., vol. 55, pp. 633-643, 2008.

[11] A. Bellini, F. Filippetti, C. Tassoni, and G. A. Capolino, "Advances in Diagnostic Techniques for Induction Machines," IEEE Trans. Ind. Electron., vol. 55, pp. 4109-4126, 2008.

[12] W. G. Zanardelli, E. G. Strangas, and S. Aviyente, "Identification of Intermittent Electrical and Mechanical Faults in Permanent-Magnet AC Drives Based on Time-Frequency Analysis," IEEE Trans. Ind. Appl., vol. 43, pp. 971-980, 2007.

[13] M. Blodt, M. Chabert, J. Regnier, and J. Faucher, "Mechanical Load Fault Detection in Induction Motors by Stator Current Time-Frequency Analysis," IEEE Trans. Ind. Appl., vol. 42, pp. 1454-1463, 2006.

[14] A. Sadeghian, Z. Ye, and B. Wu, "Online Detection of Broken Rotor Bars in Induction Motors by Wavelet Packet Decomposition and Artificial Neural Networks," IEEE Trans. Instrum. Meas., vol. 58, pp. 2253-2263, 2009.

[15] M. Khan and M. A. Rahman, "Development and Implementation of a Novel Fault Diagnostic and Protection Technique for IPM Motor Drives," IEEE Trans. Ind. Electron., vol. 56, pp. 85-92, 2009.

[16] I. P. Tsoumas, G. Georgoulas, E. D. Mitronikas, and A. N. Safacas, "Asynchronous Machine Rotor Fault Diagnosis Technique Using Complex Wavelets," IEEE Trans. Energy Convers., vol. 23, pp. 444-459, 2008.

[17] M. Riera-Guasp, J. A. Antonino-Daviu, J. Roger-Folch, and M. P. Molina Palomares, "The Use of the Wavelet Approximation Signal as a Tool for the Diagnosis of Rotor Bar Failures," IEEE Trans. Ind. Appl., vol. 44, pp. 716-726, 2008.

[18] M. Riera-Guasp, J. A. Antonino-Daviu, M. Pineda-Sanchez, R. PuchePanadero, and J. Perez-Cruz, "A General Approach for the Transient Detection of Slip-Dependent Fault Components Based on the Discrete Wavelet Transform," IEEE Trans. Ind. Electron., vol. 55, pp. 4167-4180, 2008.

[19] A. Ordaz-Moreno, R. de Jesus Romero-Troncoso, J. A. Vite-Frias, J. R. Rivera-Gillen, and A. Garcia-Perez, "Automatic Online Diagnosis Algorithm for Broken-Bar Detection on Induction Motors Based on Discrete Wavelet Transform for FPGA Implementation," IEEE Trans. Ind. Electron., vol. 55, pp. 2193-2202, 2008.

[20] J. Liu, W. Wang, and F. Golnaraghi, "An Extended Wavelet Spectrum for Bearing Fault Diagnostics," IEEE Trans. Instrum. Meas., vol. 57, pp. 2801-2812, 2008

[21] F. Briz, M. W. Degner, P. Garcia, and D. Bragado, "Broken Rotor Bar Detection in Line-Fed Induction Machines Using Complex Wavelet Analysis of Startup Transients," IEEE Trans. Ind. Appl., vol. 44, pp. 760 $768,2008$.

[22] S. Rajagopalan, J. M. Aller, J. A. Restrepo, T. G. Habetler, and R. G. Harley, "Analytic-Wavelet-Ridge-Based Detection of Dynamic Eccentricity in Brushless Direct Current (BLDC) Motors Functioning Under Dynamic Operating Conditions," IEEE Trans. Ind. Electron., vol. 54, pp. 1410-1419, 2007.

[23] F. Ponci, A. Monti, L. Cristaldi, and M. A. L. M. Lazzaroni, "Diagnostic of a Faulty Induction Motor Drive via Wavelet Decomposition," IEEE Trans. Instrum. Meas., vol. 56, pp. 2606-2615, 2007.
[24] M. A. S. K. Khan, T. S. Radwan, and M. A. Rahman, "Real-Time Implementation of Wavelet Packet Transform-Based Diagnosis and Protection of Three-Phase Induction Motors," IEEE Trans. Energy Convers., vol. 22, pp. 647-655, 2007.

[25] G. A. Jiménez, A. O. Muñoz, and M. A. Duarte-Mermoud, "Fault detection in induction motors using Hilbert and Wavelet transforms," Electrical Engineering (Archiv fur Elektrotechnik), vol. 89, pp. 205-220, 2007.

[26] J. Antonino-Daviu, P. Jover, M. Riera, A. Arkkio, and J. Roger-Folch, "DWT analysis of numerical and experimental data for the diagnosis of dynamic eccentricities in induction motors," Mechanical Systems and Signal Processing, vol. 21, pp. 2575-2589, 2007.

[27] M. Pineda-Sanchez, M. Riera-Guasp, J. A. Antonino-Daviu, J. RogerFolch, J. Perez-Cruz, and R. Puche-Panadero, "Diagnosis of Induction Motor Faults in the Fractional Fourier Domain," IEEE Trans. Instrum. Meas., vol. 59, pp. 2065-2075, 2010.

[28] O. Poncelas, J. A. Rosero, J. Cusidó, J. A. Ortega, and L. Romeral, "Motor Fault Detection Using a Rogowski Sensor Without an Integrator," IEEE Trans. Ind. Electron., vol. 56, pp. 4062-4070, 2009.

[29] M. Blodt, D. Bonacci, J. Regnier, M. Chabert, and J. Faucher, "On-Line Monitoring of Mechanical Faults in Variable-Speed Induction Motor Drives Using the Wigner Distribution," IEEE Trans. Ind. Electron., vol. 55, pp. 522-533, 2008 .

[30] A. Lebaroud and G. Clerc, "Classification of Induction Machine Faults by Optimal Time-Frequency Representations," IEEE Trans. Ind. Electron., vol. 55, pp. 4290-4298, 2008.

[31] S. Rajagopalan, J. A. Restrepo, J. M. Aller, T. G. Habetler, and R. G. Harley, "Nonstationary Motor Fault Detection Using Recent Quadratic Time-Frequency Representations," IEEE Trans. Ind. Appl., vol. 44, pp. 735-744, 2008.

[32] A. Espinosa, J. Rosero, J. Cusido, L. Romeral, and J. Ortega, "Fault Detection by Means of Hilbert-Huang Transform of the Stator Current in a PMSM With Demagnetization," IEEE Transactions on Energy Conversion, vol. 25, pp. 312-318, 2010.

[33] F. L. Niu, J. Huang, J. Q. Yang, L. Y. Chen, and H. Jin, "Rotor brokenbar fault diagnosis of induction motor based on HHT of the startup electromagnetic torque," Frontiers of Electrical and Electronic Engineering in China, vol. 1, pp. 188-193, 2006.

[34] Z. K. Peng, P. W. Tse, and F. L. Chu, "A comparison study of improved Hilbert-Huang transform and wavelet transform: Application to fault diagnosis for rolling bearing," Mechanical Systems and Signal Processing, vol. 19, pp. 974-988, 2005.

[35] C. Torrence and G. P. Compo, "A practical guide to wavelet analysis," Bull. Am. Meteor. Soc., vol. 79, pp. 61-78, 1998.

[36] N. Ahuja, S. Lertrattanapanich, and N. K. Bose, "Properties determining choice of mother wavelet," IEE Proc. Vis., Image, Signal Process., vol. 152, pp. 659-664, 2005.

[37] M. Farge, "Wavelet transforms and their applications to turbulence," Ann. Rev. of Fluid Mech., vol. 24, pp. 395-458, 1992.

[38] S. Karimi, A. Gaillard, P. Poure, and S. Saadate, "FPGA-Based RealTime Power Converter Failure Diagnosis for Wind Energy Conversion Systems," IEEE Trans. Ind. Electron., vol. 55, pp. 4299-4308, 2008.

[39] B. Akin, U. Orguner, H. A. Toliyat, and M. Rayner, "Phase-Sensitive Detection of Motor Fault Signatures in the Presence of Noise," IEEE Trans. Ind. Electron., vol. 55, pp. 2539-2550, 2008.

[40] B. Akin, U. Orguner, H. A. Toliyat, and M. Rayner, "Low Order PWM Inverter Harmonics Contributions to the Inverter-Fed Induction Machine Fault Diagnosis," IEEE Trans. Ind. Electron., vol. 55, pp. 610-619, 2008.

[41] S. M. A. Cruz, H. A. Toliyat, and A. J. M. Cardoso, "DSP Implementation of the Multiple Reference Frames Theory for the Diagnosis of Stator Faults in a DTC Induction Motor Drive," IEEE Trans. Energy Convers., vol. 20, pp. 329-335, 2005.

[42] E. Sejdic, I. Djurovic, and L. J. Stankovic, "Quantitative Performance Analysis of Scalogram as Instantaneous Frequency Estimator," IEEE Transactions on Signal Processing, vol. 56, pp. 3837-3845, 2008.

[43] M. E. K. Oumaamar, A. Khezzar, M. Boucherma, H. Razik, R. N. Andriamalala, and L. Baghli, "Neutral Voltage Analysis for Broken Rotor Bars Detection in Induction Motors Using Hilbert Transform Phase," in Conference Record of the 42th IAS Annual Meeting, New Orleans, Louisiana, 23-27 Sept., 2007, pp. 1940-1947.

[44] M. Elfataoui and G. Mirchandani, "A frequency-domain method for generation of discrete-time analytic signals," IEEE Transactions on Signal Processing, vol. 54, pp. 3343-3352, 2006. 
[45] B. Boashash, "Estimating and interpreting the instantaneous frequency of asignal. I. Fundamentals," Proceedings of the IEEE, vol. 80, pp. 520-538, 1992.

[46] Y. Chen, H. Zhenhua, and H. Deji, "Effects of Gabor transform parameters on signal time-frequency resolution," Applied Geophysics, vol. 3, pp. 169-173, 2006.

[47] M. Li and R. C. Staunton, "Optimum Gabor filter design and local binary patterns for texture segmentation," Pattern Recognition Letters, vol. 29, pp. 664-672, 2008.

[48] J. Cui and W. Wong, "Optimal Window Length in the Windowed Adaptive Chirplet Analysis of Visual Evoked Potentials," in Proc. of the 28th Annual International Conference of the IEEE Engineering in Medicine and Biology Society, New York, August 30-Sept. 3, 2006, pp. $4580-4583$.

[49] A. Akan and L. F. Chaparro, "Multi-window Gabor expansion for evolutionary spectral analysis," Signal processing, vol. 63, pp. 249-262, 1997.

[50] H. G. Feichtinger, P. Prinz, and W. Kozek, "Gabor systems with good TF-localization and applications to image processing," in Proc. International Conference on Image Processing, Lausanne, Switzerland, September 16 - 19,1996., pp. 249-252.

[51] L. Shen, L. Bai, and M. Fairhurst, "Gabor wavelets and General Discriminant Analysis for face identification and verification," Image and Vision Computing, vol. 25, pp. 553-563, 2007.

[52] B. Zhu, L. Jiang, Y. Luo, and Y. Tao, "Gabor feature-based apple quality inspection using kernel principal component analysis," Journal of Food Engineering, vol. 81, pp. 741-749, 2007.

[53] Q. Kemao, "On window size selection in the windowed Fourier ridges algorithm," Optics and Lasers in Engineering, vol. 45, pp. 1186-1192, 2007.

[54] A. E. Ibrahim, T. A. Kawady, H. A. Darwish, and A. M. Taalab, "Generalized 1-D Gabor Transform Application to Power System Signal Analysis," Industrial Electronics, 2006 IEEE International Symposium on, Montreal, Canada, 9-13 July 2006, pp. 624-629.

[55] S. Cho, G. Jang, and S. Kwon, "Time-Frequency Analysis of PowerQuality Disturbances via the Gabor-Wigner Transform," IEEE Transactions on Power Delivery, vol. 25, pp. 494-499, 2010.

[56] N. K. Subbanna and Y. Y. Zeevi, "Macromolecular sequence analysis using multiwindow Gabor representations," Signal processing, vol. 88, pp. 877-890, 2008.

[57] L. Zhuang and M. J. Crocker, "A Study of Joint Time-Frequency Analysis-Based Modal Analysis," IEEE Trans. Instrum. Meas., vol. 55, pp. 2335-2342, 2006.

[58] S. Hui, J. Wei, and Q. Shie, "Order tracking by discrete Gabor expansion," IEEE Trans. Instrum. Meas., vol. 52, pp. 754-761, 2003.

[59] J. Wexler and S. Raz, "Discrete gabor expansions," Signal processing, vol. 21, pp. 207-221, 1990.

[60] D. L. Jones and T. W. Parks, "A high resolution data-adaptive timefrequency representation," Acoustics, Speech and IEEE Transactions on Signal Processing, vol. 38, pp. 2127-2135, 1990.

[61] P. Flandrin, "A time-frequency formulation of optimum detection," Acoustics, Speech and IEEE Transactions on Signal Processing, vol. 36, pp. 1377-1384, 1988.

[62] A. Janssen, "On the locus and spread of pseudo-density functions in the time-frequency plane," Philips J. Res, vol. 37, pp. 79-110, 1982.

[63] P. Wahlberg and M. Hansson, "Kernels and Multiple Windows for Estimation of the Wigner-Ville Spectrum of Gaussian Locally Stationary Processes," IEEE Transactions on Signal Processing, vol. 55, pp. 73-84, 2007.

[64] D. Gabor, "Theory of communication," J. IEE, vol. 93, pp. 429-457, 1946.

[65] B. Friedlander and B. Porat, "Detection of transient signals by the Gabor representation," Acoustics, Speech and IEEE Transactions on Signal Processing, vol. 37, pp. 169-180, 1989.

[66] X. Jun and P. Flandrin, "Multitaper Time-Frequency Reassignment for Nonstationary Spectrum Estimation and Chirp Enhancement," IEEE Transactions on Signal Processing, vol. 55, pp. 2851-2860, 2007.

[67] A. Akan and L. F. Chaparro, "Evolutionary chirp representation of nonstationary signals via Gabor transform," Signal processing, vol. 81, pp. 2429-2436, 2001.

[68] T. P. Zielinski, "Joint time-frequency resolution of signal analysis using Gabor transform," IEEE Trans. Instrum. Meas., vol. 50, pp. 1436-1444, 2001.
[69] D. L. Jones and T. W. Parks, "A resolution comparison of several timefrequency representations," IEEE Transactions on Signal Processing, vol. 40, pp. 413-420, 1992.

[70] S. Mallat, A Wavelet Tour of Signal Processing. New York: Academic Press, 1999.

[71] N. F. Barber and F. Ursell, "The response of a resonant system to a gliding tone," Philosophical Magazine, vol. 39, pp. 345-361, 1948.

[72] A. Abbate, C. DeCusatis, and P. K. Das, Wavelets and subbands: fundamentals and applications. Boston, MA: Birkhäuser, 2002.

[73] V. Bargmann, P. Butera, L. Girardello, and J. R. Klauder, "On the completeness of the coherent states," Reports on Mathematical Physics, vol. 2, pp. 221-228, 1971.

[74] M. Boon and J. Zak, "Discrete coherent states on the von Neumann lattice," Physical Review B, vol. 18, pp. 6744-6751, 1978.

[75] T. Werther, E. Matusiak, Y. C. Eldar, and N. K. Subbana, "A Unified Approach to Dual Gabor Windows," IEEE Transactions on Signal Processing, vol. 55, pp. 1758-1768, 2007.

[76] A. J. E. M. Janssen and T. Strohmer, "Characterization and Computation of Canonical Tight Windows for Gabor Frames," Journal of Fourier Analysis and Applications, vol. 8, pp. 1-28, 2002.

[77] P. Prinz, "Calculating the dual Gabor window for general sampling sets," IEEE Transactions on Signal Processing, vol. 44, pp. 2078-2082, 1996.

[78] I. Daubechies and A. J. E. M. Janssen, "Two theorems on lattice expansions," IEEE Transactions on Information Theory, vol. 39, pp. 3-6, 1993.

[79] L. Auslander, I. C. Gertner, and R. Tolimieri, "The discrete Zak transform application to time-frequency analysis and synthesis of nonstationary signals," IEEE Transactions on Signal Processing, vol. 39, pp. 825-835, 1991.

[80] A. J. E. M. Janssen and P. L. Søndergaard, "Iterative Algorithms to Approximate Canonical Gabor Windows: Computational Aspects," Journal of Fourier Analysis and Applications, vol. 13, pp. 211-241, 2007.

[81] M. J. Bastiaans, "Gabor's expansion of a signal into Gaussian elementary signals," Proceedings of the IEEE, vol. 68, pp. 538-539, 1980.

[82] M. J. Bastiaans and M. C. W. Geilen, "On the discrete Gabor transform and the discrete Zak transform," Signal processing, vol. 49, pp. 151-166, 1996.

[83] M. Bastiaans, "On the sliding-window representation in digital signal processing," Acoustics, Speech and IEEE Transactions on Signal Processing, vol. 33, pp. 868-873, 1985.

[84] T. Strohmer, "Numerical algorithms for discrete Gabor expansions," in Gabor analysis and algorithms: Theory and applications. Boston, MA: Birkhäuser, 1998, pp. 267-294.

[85] M. J. Bastiaans, "Gabor's signal expansion and its relation to sampling of the sliding-window spectrum," in Advanced Topics in Shannon Sampling and Interpolation Theory, R. J. Marks, Ed. New York: Springer, 1993, pp. $1-35$.

[86] T. T. Wang, "The segmented chirp Z-transform and its application inspectrum analysis," IEEE Trans. Instrum. Meas., vol. 39, pp. 318-323, 1990.

[87] M. Aiello, A. Cataliotti, and S. Nuccio, "A chirp-z transform-based synchronizer for power system measurements," IEEE Trans. Instrum. Meas., vol. 54, pp. 1025-1032, 2005.

[88] P. Soo-Chang and Y. Ing-Ing, "High resolution Wigner distribution using chirp Z-transform analysis," IEEE Transactions on Signal Processing, vol. 39, pp. 1699-1702, 1991.

[89] X. Xiang-Gen, "Discrete chirp-Fourier transform and its application to chirp rate estimation," IEEE Transactions on Signal Processing, vol. 48, pp. 3122-3133, 2000.

[90] L. Rabiner, R. Schafer, and C. Rader, "The chirp z-transform algorithm," IEEE Transactions on Audio and Electroacoustics, vol. 17, pp. 86-92, 1969.

[91] L. R. Rabiner, R. W. Schafer, and C. M. Rader, "The chirp z-transform algorithm and its application," Bell Sys. Tech. J, vol. 48, pp. 1249-1291, 1969.

[92] M. Palmese and A. Trucco, "Three-Dimensional Acoustic Imaging by Chirp Zeta Transform Digital Beamforming," IEEE Trans. Instrum. Meas., vol. 58, pp. 2080-2086, 2009.

[93] M. Aiello, A. Cataliotti, and S. Nuccio, "An induction motor speed measurement method based on current harmonic analysis with the chirpZ transform," IEEE Trans. Instrum. Meas., vol. 54, pp. 1811-1819, 2005.

[94] M. J. Bastiaans, "Application of the Wigner distribution function to partially coherent light," Journal of the Optical Society of America A, vol. 3, pp. 1227-1238, 1986. 